\title{
Historiografia literária brasileira oitocentista: um ciclo de estudos (1996-2015)*
}

Roberto Acízelo de Souza ${ }^{a}$

\section{Resumo}

Descreve-se um extenso ciclo de pesquisa sobre as obras fundadoras da historiografia da literatura brasileira, da ideia inicial à publicação dos resultados, ao mesmo tempo em que se empreende uma reflexão sobre os vários aspectos de todo o processo.

Palavras-chave: literatura brasileira; historiografia literária; obras fundadoras.

\footnotetext{
* Trabalho apresentado no I Seminário do Programa de Pós-Graduação em Literatura Brasileira da Universidade de São Paulo, realizado de 9 a 13 de março de 2015, bem como no VI Seminário dos Alunos dos Programas de Pós-Graduação do Instituto de Letras da Universidade Federal Fluminense, que teve lugar nos dias $22 \mathrm{e}$ 23 de setembro de 2015.
}

\footnotetext{
a Universidade do Estado do Rio de Janeiro / CNPq / FAPERJ, acizelo@bighost.com.br
} 
1

Proponho-me a descrever um extenso ciclo de pesquisa, da ideia inicial à publicação de seus resultados e, ao mesmo tempo, empreender uma reflexão acerca dos vários aspectos do processo, nos planos metodológico e teórico, e não sem resvalar em plano ainda mais fluido, que talvez tolere o qualificativo de existencial. Trata-se, pois, de reconstituir os passos de uma experiência concreta de pesquisa, em que se pretende falar não só da corrida, mas também do tombo, na expectativa de que o relato possa interessar aos que se dedicam a estudos especializados no campo das humanidades, muito especialmente aos estudantes, pesquisadores em formação.

Os jovens talvez se espantem com a longa duração do ciclo em referência: 1996 a 2015, isto é, quase 20 anos, pouco menos do que a idade de muitos pós-graduandos, e cerca de dois terços do tempo necessário para um trabalhador se aposentar. Apresso-me, contudo, em dizer que não me dei conta do decurso de tantos anos, senão agora quando reunia apontamentos para elaborar meu texto, e isso pelo menos por três razões: primeiro porque a fuga do tempo, conforme assinalou Guimarães Rosa, só como um "devagar depressa"1, é que se dá a perceber; segundo porque, nesse ínterim, não foi só a história da literatura que constituiu meu objeto de estudo; e finalmente porque, como adiante explico, boa parte desses anos se preencheram não com as pesquisas propriamente ditas, mas com a longa expectativa da publicação dos ensaios e livros resultantes do trabalho.

\section{2}

Começo dando conta de como despertei para a conveniên-

1 "Os tempos mudavam, no devagar depressa dos tempos" (João Guimarães Rosa, no conto "A terceira margem do rio").

2 A tese foi posteriormente publicada em livro: O império da eloquência: retórica e poética no Brasil oitocentista. Rio de Janeiro: Eduerj; Niterói, RJ, Eduff, 1999. cia de um estudo mais detalhado dos projetos de história da literatura nacional do Brasil concebidos e executados ao longo do século XIX. Em 1994, com vistas a concurso para professor titular da minha universidade, preparei uma tese sobre um aspecto da nossa cultura literária oitocentista pouco conhecido: a persistência, em pleno século romântico, de uma concepção clássica das letras, atestada no ensino de literatura da época, e no prestígio alcançado pelos manuais de retórica e poética produzidos no período. ${ }^{2}$ Fiz então um estudo minucioso des- 
3 A informação consta da p. 2 do mencionado volume Historiadores $e$ críticos do romantismo, onde figura, na lista dos "próximos lançamentos" da editora, o título Historiadores e críticos românticos - II, III (seleção e apresentação de Guilhermino César). ses materiais, e depois, como estratégia analítica, procurei contrastar o pensamento retórico-poético tardio, clássico e universalista, com o historicismo literário romântico e nacionalista que nesse momento despontava. $\mathrm{O}$ saldo dessa trajetória posso dizer que foi duplo: se, por um lado, me satisfez o que pude aprender acerca da vertente retórico-poética, por outro lado constatei como permanecia acanhado o meu conhecimento da corrente historicista. De fato, fora os autores reeditados na nossa época - Romero, Araripe, Veríssimo -, limitava-se a comentários e notícias de segunda mão, lidos em estudos sobre a história da "crítica" brasileira, e aos autores estrangeiros comodamente disponibilizados por Guilhermino César num prestimoso volume publicado em 1978: Historiadores e críticos do romantismo: 1 - a contribuição europeia: crítica e história literária. Em face dessa constatação, e diante da necessidade profissional de iniciar novo projeto de pesquisa (concluído o que redundara na tese do concurso), achei que poderia escolher como tema, justamente, a para mim semidesconhecida produção de nossos historiadores literários do Oitocentos. E como sabia que estivera nos planos de Guilhermino César dar sequência a seu trabalho com mais dois volumes, que, como tudo indicava, coberta "a contribuição europeia", se dedicariam à recuperação dos ensaios fundadores de nossa história literária produzidos por autores brasileiros, ${ }^{3}$ procurei saber, com pessoas de sua relação, se o mestre, morto em 1993, teria deixado inéditos em vias de publicação. Como o resultado da sondagem foi negativo, concluí que tinha à minha disposição um campo fértil para trabalhar, e foi assim que, tendo feito o concurso mencionado no início de 1995, esperei a poeira baixar, para enfim, a partir de 1996, começar o mapeamento do terreno e logo depois dar início efetivo à recolha e ao estudo dos textos, com o objetivo remoto de disponibilizar para a nossa comunidade estudiosa algo equivalente aos volumes que o professor Guilhermino planejara e não chegara a produzir.

A seleção de materiais foi, assim, a primeira etapa do processo. Recorri, claro, para o inventário, todos os nossos grandes tratados de história literária nacional - além de alguns menos notórios -, bem como os poucos trabalhos dedicados à produção brasileira do gênero dito "história da crítica". Recorri, também, aos subsídios fornecidos pelo número de junho de 1995 dos Cadernos do Centro de Pesquisas Literárias da PUCRS 
4 Outras contribuições das autoras me foram muito úteis e estimulantes no processo da pesquisa, especialmente o número de agosto de 1999 dos referidos $\mathrm{Ca}$ dernos ("Crítica literária romântica no Brasil: primeiras manifestações") além, naturalmente, do volume $O$ berço do cânone: textos fundadores da história da literatura brasileira, de 1998, o qual em parte antecipava a publicação de materiais que eu então ia organizando com vistas a recolher no livro que planejava. O mesmo devo dizer da edição do Bosquejo da história da poesia brasileira, de Joaquim Norberto, preparada por José Américo Miranda e publicada em 1997. Por fim, registro ainda o misto de satisfação e frustração com que recebi, já concluída a pesquisa e quase em ponto de ir para a gráfica, a minha edição da História de Norberto, Os capítulos de história da literatura brasileira e outros estudos, do mesmo Norberto, em cuidadosa edição organizada por José Américo Miranda e Maria Cecília Boechat, e lançada em 2001. Compreenda-se: satisfação, porque consolidava a sensação de não estar tão sozinho no meu labor; e frustração, porque, afinal, Minas Gerais arrebatava ao Rio de Janeiro a primazia em produzir a primeira edição em livro da historiografia literária norbertiana.
("História da literatura e literatura brasileira"), organizado por Regina Zilberman e Maria Eunice Moreira. ${ }^{4}$ Para a escolha dos autores, já dispunha de um critério: considerando que Guilhermino César se ocupara com a "contribuição europeia", propunha-me dar conta das obras produzidas por autores brasileiros, ou radicados no Brasil, como concluiria depois, flexibilizando o critério no curso da pesquisa. Quanto ao lapso de tempo a ser coberto, deliberei que partiria do esboço mais antigo de uma historiografia literária nacional - o Parnaso brasileiro, organizado por Januário da Cunha Barbosa, de 1829 a 1832, até um ensaio de Araripe Júnior de 1886 - "Ponto de vista para o estudo da literatura brasileira" -, última produção por mim identificada anterior ao marco que tomei como consolidação do processo, a meu ver, sem contestação possível, a História da literatura brasileira de Sílvio Romero, publicada em 1888. Mais tarde, no entanto, com o desenvolvimento dos estudos, acabaria estendendo um pouco essas balizas, e assim prevaleceu, como marco cronológico, uma carta de José Bonifácio, datada de 1825, onde, salvo novas descobertas, pela primeira vez se emprega a expressão "história literária do Brasil", e um trecho referente às letras do livro $A$ arte brasileira, de Luís Gonzaga Duque-Estrada, publicado em 1888, porém antes da História de Romero. Por fim, um último critério limitou a escolha a estudos de intenções generalistas, desconsiderando-se, portanto, ensaios sobre obras ou autores específicos, salvo nos casos em que tais ensaios ampliassem o foco para considerações relativas ao conceito de literatura brasileira e sua história.

\section{3}

Com base, assim, no levantamento em fontes secundárias, orientado pelos parâmetros referidos, parti para os fichários de bibliotecas, na época ainda não informatizados, a fim de localizar as fontes primárias. Explorei principalmente a Biblioteca Nacional, mas também as bibliotecas do Instituto Histórico e Geográfico Brasileiro, da Academia Brasileira de Letras e da Faculdade de Letras da UFRJ, além do acervo de livros do Arquivo Nacional. Iniciava-se, então, uma etapa do trabalho que se revelaria lenta e um tanto penosa. Na suposição de não ser excessivo, neste empenho de reconstituição da experiência, vou deter-me um pouco na descrição do processo, 
mesmo sabendo que hoje, mais de 15 anos depois, as condições tecnológicas melhoraram bastante, e as institucionais, embora longe do desejável e possível, também passaram por certo aperfeiçoamento. Vejamos então um flash do que era a pesquisa bibliográfica na segunda metade da década de 1990 no Brasil, e qualquer semelhança com o estado de coisas de hoje é perfeitamente previsível, não obstante os mencionados progressos tecnológicos.

A burocracia era grande, e os equipamentos, quando existiam, poucos e antiquados, de modo que a necessidade de uma simples cópia xerográfica - nas instituições e nas situações em que esse recurso era permitido - usualmente se transformava num problema. Para se fazer ideia do tempo despendido nessas operações de acesso material aos textos, veja-se a sequência de passos então necessários na Biblioteca Nacional: em primeiro lugar, vinha a providência de localizar os livros e periódicos - em geral pertencentes ao setor de obras raras daquela instituição -, em fichários antigos e não informatizados, a fim de requisitá-las para exame, podendo os textos se apresentarem nos impressos oitocentistas ou sob a forma de microfilmes; em seguida, se o texto se revelasse pertinente segundo os critérios da pesquisa, vinha a requisição de cópia, o que por sua vez implicava: solicitar um orçamento, só fornecido em cerca de uma semana; efetuar o pagamento do serviço; aguardar a microfilmagem, quando se tratava de textos ainda não disponíveis em microfilme (caso da grande maioria dos que se revelaram pertinentes), o que demorava cerca de mais 15 dias; solicitar cópia eletrostática do microfilme, para se dispor do texto em suporte de papel, com vistas à leitura e à digitação, processo que por sua vez demandava outros 15 dias de espera. Essa rotina podia variar um pouco, inclusive de acordo com os regulamentos de cada instituição, às vezes para melhor - quando, por exemplo, era permitido xerografar certas obras, processo bem mais simples, barato e rápido -, às vezes para pior - quando se fazia necessário copiar manualmente longas passagens, na falta de expediente mais prático -, mas a regra consistia em aguardar um pouco mais de um mês para se ter o texto em mãos, só então sendo possível passar à etapa subsequente. Como na época já existisse o recurso, fiz uma tentativa de iniciar a editoração, escaneando os textos, o que, contudo, não deu certo: os originais, todos antigos, apre- 
sentavam muitas manchas que as cópias reproduziam, e assim os arquivos resultantes do escaneamento apresentavam tantos erros que foi preciso digitar integralmente todos os textos, processo muito mais demorado e oneroso. ${ }^{5}$

A digitação, recomendei que se fizesse de modo mecânico, conservando-se, num primeiro momento, a ortografia e a pontuação das edições-fonte, para em seguida se aplicar um corretor eletrônico, a fim de processar-se uma atualização ortográfica preliminar e sumária. Feito isso, foi a minha vez de proceder a uma revisão minuciosa, para acertar os detalhes textuais que por natureza escapavam à correção automática, bem como para modernizar a pontuação e introduzir notas explicativas. Não fossem os recursos da editoração eletrônica, que permitiam correções ortográficas automáticas e depois intervenções nos textos executadas diretamente no vídeo - refinamento da revisão, alteração da pontuação, introdução de notas, esboço enfim da programação visual da publicação futura -, sem necessidade, portanto, de impressão, não fossem essas facilidades, as 1.700 páginas do arquivo resultante da recolha dos textos certamente não teriam sido estabelecidas em apenas dois anos e meio. É que, como venho do tempo da datilografia, nem preciso imaginar - por saber muito bem - o que teria sido essa etapa do trabalho sem os meios de processamento eletrônico de textos de que passamos a dispor a partir dos anos de 1990, tão espantosamente distanciados da tecnologia com que desde então podemos contar. Limitados a máquinas de escrever simplíssimas, emendando textos com lápis ou caneta, impossibilitados de obter cópias em série, fazendo recortes e colagens não virtuais, mas com tesoura e cola bem reais, quanto mais não se teria prolongado esse estágio do projeto?

5 Este parágrafo e o subsequente incorporam, com a devida revisão e ajustes, trecho de ensaio anteriormente publicado: Textos fundadores da historiografia literária brasileira: descrição da pesquisa e análise preliminar. Vínculo: revista de Letras da Unimontes, Montes Claros, MG, v. 3, n. 1, p. 21-43, dez. 2002.
4

Mas, então, dois anos e meio depois de iniciado o projeto, já dispunha, em meados de 1998, de um considerável acervo de textos devidamente processados. Foi quando achei que um dos autores, objeto da pesquisa - Joaquim Norberto de Sousa Silva -, pela extensão e pelo pioneirismo de sua projetada e incompleta história da literatura brasileira, até então inédita em livro, merecia tratamento à parte. Priorizei, assim, a fixação de seus textos, preparando uma edição de sua obra que intitulei 
História da literatura brasileira e outros ensaios, constituída por apresentação, notas, cronologia, bibliografia ativa e passiva, índice onomástico-temático e caderno de ilustrações, volume que seria publicado em 2002, e sobre o qual adiante me detenho um pouco. Depois, no entanto, do desvio representado pelo tratamento dos textos de Joaquim Norberto, voltando à estrada real, passei à redação das apresentações de cada um dos demais autores, segundo um padrão que combinava dados biobibliográficos minuciosos e sistemáticos com uma notícia crítica acerca do(s) texto(s) selecionado(s). Finalmente, redigida a apresentação geral do conjunto, pude dar por concluída a empreitada, isso já no primeiro semestre de 2000. Descrevo a seguir a estrutura da obra, que então considerava acabada e pronta para publicação.

Pensei em atribuir-lhe o título de Uma literatura original nos trópicos, por caracterizar a militância de nossos letrados oitocentistas, desdobrada do imediato pós-independência até as imediações da proclamação da república, no sentido de instaurar no Brasil uma cultura literária própria, e cogitei de determinar melhor o conteúdo da obra por um subtítulo, que seria "Textos fundadores da historiografia da literatura brasileira". Além da apresentação geral, a publicação, no estágio em que se encontrava na ocasião, contava com 40 módulos, constituído cada qual de uma apresentação específica do(s) autor(es) e respectivas referências bibliográficas, seguidas por seus textos, editados com ortografia e pontuação atualizadas, além de dotados de notas explicativas. Pela extensão do arquivo, calculava que a publicação viria a ocupar cinco volumes, cada um deles em torno de 450 páginas.

Bem, é fácil prever as dificuldades que logo comecei a enfrentar para encontrar editor que se interessasse pelo original, dificuldades que, de resto, desde o início do projeto não ignorava que teria. No entanto, batendo às portas que me estavam mais próximas - as das editoras universitárias da UFF e da UERJ -, tive o projeto aprovado, mas, em face da crônica falta de verbas de ambas as editoras, acabou-se caindo no esquecimento, até porque, às voltas com outras publicações, especialmente a do volume dedicado à obra historiográfica de Joaquim Norberto, decidi não insistir muito no assunto. Tentei depois a editora da USP, e obtive um parecer favorável do consultor, embora com algumas observações restritivas, mas a direção da editora me participou que não poderia bancar a 
publicação, por serem excessivamente dispendiosos os custos gráficos. Tentei, enfim, a editora da Unicamp, mas desisti de continuar o pleito, em face da exigência de enviar não sei quantos exemplares dos cinco volumes do original, o que, na época, implicava despesas de impressão, encadernação e correios que julguei impagáveis. Em face de tais obstáculos, e afinal envolvido com outros projetos acadêmicos, esqueci por muito tempo o original, concluindo que só me restava esperar por oportunidades melhores.

Como, entretanto, tinha conseguido meios de publicar o livro dedicado à produção de Joaquim Norberto, resolvi, por sugestão do editor da obra, José Mário Pereira, compactar os primitivos cinco volumes em apenas dois. Assim, depois de ter saído a edição da História de Norberto, me dediquei, no ano de 2005, à reestruturação do trabalho, começando por suprimir quase todo o módulo consagrado a Norberto, reduzindo-o a uma pequena amostra representativa de sua obra, afinal já publicada em volume independente. Procedi da mesma maneira com dois outros autores de obra extensa, contemplados na coletânea - Joaquim Caetano Fernandes Pinheiro e Francisco Sotero dos Reis -, deixando nela somente uma curta parte de suas respectivas contribuições, ao mesmo tempo que remanejava seus textos para a edição de volumes específicos, para os quais oportunamente me propunha procurar editores. Cortei também, sem dó, um longo ensaio de Álvares de Azevedo que inicialmente tinha aproveitado na íntegra, conservando somente, de suas 70 páginas, as três que diretamente tratavam de literatura brasileira. Por outro lado, eliminei as extensas referências bibliográficas que se seguiam aos textos de apresentação de cada autor. Com tais providências, em princípio só fiz aumentar minha gaveta de inéditos, que passou a contar, além da versão reduzida do planejado Uma literatura original nos trópicos, com um livro dedicado aos escritos de Fernandes Pinheiro e outro à primeira reedição do pioneiro Curso de literatura portuguesa e brasileira, de Sotero dos Reis, bem como com material para um livrinho que viesse a disponibilizar, pela primeira vez, numa edição decente e anotada, o frenético ensaio de Álvares de Azevedo intitulado "Literatura e civilização em Portugal". A estratégia da fragmentação do conjunto, no entanto, acabou dando certo, pois aos poucos as publicações se foram viabilizando. 
A seguir, me ocupo separadamente dos diversos resultados a que cheguei com o projeto, em termos de edições, tratando de cada um deles na ordem em que foram sendo publicados.

\section{1}

Como disse, inaugurou a série o volume da História da literatura brasileira e outros ensaios, de Joaquim Norberto, que saiu em 2002. Foi um exercício difícil a edição, por causa da profusão de notas e do capilarizado sistema de inter-remissão adotado, bem como, sobretudo, por conta das trabalhosas seções constituídas pela tábua cronológica - do autor, do País e do exterior - e pelo índice onomástico-temático. Na verdade, como logo compreenderia, a edição representou uma espécie de protótipo das que viriam depois. Assim, nas subsequentes, muitos dispositivos e critérios editoriais se conservaram como, por exemplo, as intervenções modernizantes na pontuação dos textos e o padrão de referência às edições-fonte - mas, ao mesmo tempo, alguns aspectos foram aperfeiçoados. $\mathrm{O}$ formato das notas, por exemplo, foi alterado, a fim de torná-las mais concisas e mais funcionais, e ao mesmo tempo, mais uniformes na sua redação. Em termos, porém, de iconografia, foi este livro de longe a mais rica das edições da série.

Gostaria, ainda, de destacar o que hoje reconheço como excesso de intervencionismo na montagem da edição. Explico: Norberto não chegou a publicar na íntegra sua História da literatura brasileira; ele foi publicando, num periódico da época, a Revista Popular, sem qualquer ordem reconhecível, os capítulos que ia escrevendo; depois, certo número do periódico estampou, como nota a um dos capítulos, o plano geral da obra, sua subdivisão em livros e capítulos. Pois bem: achei que podia tomar a liberdade de preencher algumas partes do plano - não publicadas ou talvez sequer escritas pelo autor - com outros ensaios seus cujo tema se encaixava razoavelmente nas lacunas. Foi assim que, na edição que montei, remanejei um pequeno artigo publicado autonomamente - "Poesia dos selvagens brasileiros" - para o capítulo "Tendência dos selvagens brasileiros para a poesia", que assim teve uma terceira parte acrescentada às duas nele colocadas pelo autor. Do mesmo modo, com o 
texto "Estudos sobre a literatura brasileira durante o século XVII", também antes publicado autonomamente, preenchi o vazio do "Livro terceiro: século $2^{\circ}(1600)$ ", previsto no plano geral mencionado. Finalmente, com o mesmo critério, calafetei a brecha do "Livro quarto: século $3^{\circ}(1700)$ " com o ensaio "As academias literárias e científicas no século décimo oitavo: a academia dos seletos". Hoje, contudo, reconheço que o resultado foi algo artificial, e teria feito melhor se tivesse publicado à parte os tais capítulos que incorporei à História, a exemplo, aliás, da edição da obra assinada por José Américo Miranda e Maria Cecília Boechat, a que me referi na nota 5.

\section{2}

O estudo de Joaquim Norberto suscitou ainda outra publicação meio lateral em relação ao projeto, mas que convém mencionar. É que, disponíveis duas edições de sua obra de historiografia literária (a de José Américo Miranda e Maria Cecília Boechat, e a minha), e tendo eu conhecimento dos estudos do autor, empreendidos por José Américo Miranda e Maria Eunice Moreira, propus àqueles colegas que organizássemos em colaboração uma edição de sua obra crítica, isto é, seus ensaios e estudos dedicados a autores específicos. Foi assim que, num lapso de tempo que considero curto (terá sido, se bem me lembro, em torno de um ano), organizamos e publicamos um volume - Crítica reunida (1850-1892) -, que saiu em 2005, e que enfeixou - acredito - toda a produção norbertiana no campo da crítica stricto sensu.

\section{3}

Na linha central do projeto, viria em seguida, depois de um considerável intervalo de cinco anos, o volume dedicado a Fernandes Pinheiro, que teve por título Historiografia da literatura brasileira: textos inaugurais, aparecido em 2007. Trata-se, do mesmo modo que os dois livros anteriores consagrados aos escritos de Norberto, de edição que julgo criteriosa e confiável, e dotada de um sistema de notas mais aperfeiçoado em relação ao primeiro da série. Ressente-se, porém, de um pequeno defeito editorial, pois o segundo segmento do título - "textos 
inaugurais" - acabou permanecendo graficamente indeciso entre a condição de parte do título e subtítulo: na capa, separa-se do primeiro segmento por dois pontos, o que indica ser parte do título; mas, ao mesmo tempo, apresenta-se com caracteres menores do que os usados no primeiro segmento, o que é próprio dos subtítulos; e, na folha de rosto, contraditoriamente, se investe por completo da condição de subtítulo, pois vem abaixo do título, em caracteres menores do que este e sem ser precedido pelos dois pontos. Bem, é só um detalhe de edição, que talvez a maioria dos leitores não terá percebido, e que está longe de comprometer a qualidade geral do texto, que considero plenamente satisfatória.

\section{4}

Quanto ao resultado principal do projeto, o pretendido Uma literatura original nos trópicos, permaneceu dormitando na gaveta por muito tempo, na sua segunda versão - digamos - revista e reduzida, pronta desde 2005. Por fim, ante uma perspectiva concreta de publicação, voltei a trabalhar intensivamente no original, ao longo do segundo semestre de 2013, ocasião em que, além de alguns novos cortes e revisão geral para atualização ortográfica, fiz alguns ajustes pontuais no texto e procurei aperfeiçoar o sistema de referências e notas. E não excluo a possibilidade de, no meio tempo compreendido entre 2005 e 2013, ter introduzido uma ou outra modificação de pouca monta no arquivo da obra, ainda que não tenha mantido uma memória de tais prováveis intervenções. Mas o fato é que, embora consideravelmente reduzida em relação à primeira versão, o original que acabou publicado teve o seu número de módulos aumentado, passando dos 40 iniciais para 41, com o acréscimo de uma seção que contemplou a deslembrada contribuição de Odorico Mendes. Por outro lado, alguns poucos textos vieram a acrescentar-se aos módulos já existentes, todos muito pouco conhecidos: dois ensaios juvenis respectivamente de Bernardo Guimarães e de Alencar, do tempo em que os autores eram estudantes da Faculdade de Direito de São Paulo, e uma intervenção em congresso de José Veríssimo, escrita em francês e só agora traduzida e publicada em livro. 
A publicação, enfim, se concretizou em 2014. A espera foi longa, mas terá valido a pena, se, como acredito, a terceira versão da obra, a que cheguei em 2013, efetivamente contiver substanciais aperfeiçoamentos em relação ao original de 2000, entre os quais a mudança do título, que passou a ser Historiografia da literatura brasileira: textos fundadores (1825-1888).

Trata-se de um amplo acervo, que contempla 42 autores, desde nomes óbvios e previsíveis, a exemplo de Magalhães, Gonçalves Dias, Alencar, Machado, até figuras praticamente desconhecidas, como um certo Ferreira Dias, acerca do qual pouco apurei além do sobrenome. Incluí, ainda, nomes que normalmente associamos a outras áreas, como a história política, casos de José Bonifácio e Abreu e Lima; os estudos de história, como Capistrano de Abreu; os de etnografia, como Couto de Magalhães; os trabalhos de tradução, como Odorico Mendes; o ensino de retórica, casos de Paula Meneses e Costa Honorato. Quanto aos textos recolhidos, também é grande a diversidade, inclusive de gêneros, estendendo-se de documentos muito pouco conhecidos (por exemplo, a carta de José Bonifácio, que abre a série) a peças famosas, como o ensaio "Instinto de nacionalidade", de Machado de Assis.

6 Além do trabalho das edições, por natureza quase desprovido de dimensão interpretativa, o projeto resultou ainda numa série de ensaios crítico-analíticos acerca dos materiais levantados na pesquisa, que seriam publicados, autonomamente, de 1997 a 2005. Mais tarde, juntamente com alguns estudos inéditos, foram esses ensaios sistematizados num pequeno volume, por sugestão de José Luís Jobim, que os publicou, em 2007, sob o título de Introdução à historiografia da literatura brasileira, na série Ponto de Partida, por ele dirigida para a Eduerj.

\section{5}

Em janeiro deste ano, por fim, embora também com data de 2014, saiu o volume dedicado a Sotero dos Reis, primeira reedição, ainda que parcial, de sua obra pioneira de 1866-1873. Mantive o título da primeira edição - Curso de literatura portuguesa e brasileira -, mas, como dos seus seis volumes selecionei apenas os capítulos teóricos introdutórios e os consagrados a escritores nacionais, acrescentei um subtítulo que explicitasse a escolha: "Fundamentos teóricos e autores brasileiros". De novo, ante a perspectiva de publicação, retomei o arquivo, esquecido na gaveta desde 2005, para uma inspeção geral. Acabei estendendo e aperfeiçoando bastante o estudo introdutório, tendo ainda, além da revisão geral, introduzido alterações pontuais no texto e melhorado o sistema de referências e notas. Creio tratar-se de uma bela edição, possivelmente, como edição, a melhor da série, pois beneficiária da experiência acumulada com as publicações anteriores. ${ }^{6}$ 
Até aqui, me limitei a descrever a experiência da pesquisa e a apresentar uma espécie de histórico das edições dos seus produtos. Convém, no entanto, arriscar algumas considerações conceituais sobre o trabalho realizado, refletindo um pouco sobre seus fundamentos e sobre o que podem representar como contribuição válida para nossa área de estudos.

Começo referindo um sentimento que me acompanhou o tempo todo enquanto desenvolvia o projeto, como uma sombra inarredável: a ideia incômoda de que me empenhava em algo supérfluo, talvez até desnecessário, além de desprovido de certo arrojo interpretativo que se espera dos assim chamados críticos. Pois, pensando bem, de que servia recuperar textos em geral esquecidos? Nesse sentido, não perdia de vista um juízo de René Wellek, sobre Gustave Lanson, cuja obra, segundo o justamente famoso professor austríaco, pouco teria de propriamente crítica, já que majoritariamente extraviada em "pur[o] antiquarianismo: textual, editorial, bibliográfico, estudo de fontes, etc." (WELLEK, 1972, p. 71). Por outro lado, não me esquecia do papel modesto que Erich Auerbach reservava aos praticantes do que chamava "ciências auxiliares" dos estudos literários, as quais, embora exigindo deles "toda a preparação técnica necessária para o trabalho erudito, não lhe[s] permite[...] pôr em evidência suas próprias ideias e sua própria força criadora, se as tiver" (AUERBACH, 1970, p. 27). Por fim, me lembrava sempre da passagem em que Sílvio Romero estabelece, no ofício das letras, níveis hierárquicos de desempenho, na crueza da seguinte afirmação: "[...] numa literatura há duas classes de obreiros, aqueles que produzem em qualquer esfera, na poesia ou na crítica, na história ou na filosofia, e aqueles que propalam o que os outros fizeram, que reúnem os trabalhos alheios esparsos [...]" (ROMERO, 1953, p. 559).

Enfim, então podia ser isto: falta de ideias próprias, coisa de antiquário ou de obreiro improdutivo. No entanto, apesar de seriamente advertido para a possível desnecessidade do trabalho encetado, sempre fazia uma espécie de contraponto interior, que me estimulava a prosseguir: afinal, num tempo em que a história da literatura, como circunscrição disciplinar dos estudos literários, se tornou objeto de questionamentos tão devastadores, não seria oportuno remontar às suas origens, 
tomando como exemplo o caso brasileiro, para uma reavaliação de seus fundamentos? Cumulativamente, será que não valia à pena recuperar os esboços oitocentistas da história literária nacional, a fim de desnaturalizar seus produtos acabados aparecidos a partir de 1888, e assim, por uma recomposição da trajetória da disciplina, reconhecer claramente seu caráter de construção, tão histórica quanto são, por sua vez históricos, seus próprios objetos? E mais: considerando que, muito provavelmente, as mais recentes leituras extensivas desses materiais oitocentistas se deram nos distantes anos de 1950 (penso em estudos como os de Antonio Candido e Afrânio Coutinho), não seria hora de voltarmos a eles, sem intermediações, conforme de resto a regra saudável de se retornar de tempos em tempos às fontes primárias, sob pena de se repetirem interpretações rotinizadas? Ora, visto que, como se terá percebido, minha propensão é responder positivamente a todas essas perguntas, embora tendo sempre presentes os mencionados juízos de Wellek, Auerbach e Romero, o trabalho afinal vem chegando a termo, agora faltando pouco para eu o dar por encerrado.

\section{7}

Acho que agora convém falar um pouco da recepção do trabalho de que tenho tido notícia.

A primeira data de 2003, e diz respeito, pois, à primeira versão do que viriam a ser os dois volumes do Historiografia da literatura brasileira: textos fundadores (1825-1888). Trata-se de parecer de um consultor da Edusp, desidentificado, portanto. Como disse antes, o parecer recomendou a publicação da obra, mas fez algumas sugestões e comentários restritivos, bastante pertinentes, aliás. Sugeria, como antes já o fizera o editor José Mário Pereira, a redução das dimensões do original, pela supressão da parte dedicada a Norberto, então já publicada, bem como pela eliminação das bibliografias dos diversos módulos. Recomendava ainda, contra o critério explícito que eu adotara, a inserção de pequenas notas biobibliográficas, e também assinalava a necessidade de "inclusão de um ensaio introdutório de maior fôlego".

Assim, a redução das dimensões, como vimos, foi de fato providenciada, mas não a inclusão de mais notas, e, quanto ao texto da introdução geral, substancialmente permaneceu 
o mesmo na publicação definitiva, salvo um ou outro retoque que terá sofrido nas sucessivas revisões. Mas não retiro com isso a razão do consultor: na verdade, teria sido muito útil aos leitores a inserção das tais notas reclamadas, e o texto da introdução de fato era muito sumário, não chegando a ocupar quatro páginas das 583 do primeiro volume. Quanto às notas, minha justificativa está nos próprios "Critérios da edição", item 5, onde se informa que, importando mesmo "a compreensão do sistema conceitual dos ensaios", deixava-se por conta do leitor "a explicação de [...] miudezas enciclopédicas", e acrescento, o que lá não foi dito: o acréscimo das notas me tomaria um tempo de que não dispunha, sem que - suponho - o benefício do leitor viesse a ser proporcional ao meu esforço. Quanto ao pouco desenvolvimento do ensaio de introdução, reconhecendo que procede a observação do consultor, acho, contudo, francamente, que assinalei o que devia. Assim, caracterizei o gênero história da literatura; falei do seu desenvolvimento no Brasil do século XIX; defini, justificando-o, o âmbito cronológico que a publicação se propunha cobrir, e justifiquei a pertinência da coletânea; propus uma distribuição por classes dos vários textos reunidos na publicação - introduções a antologias; declarações de princípios sobre o projeto literário nacional do Brasil; sínteses históricas da literatura brasileira; introduções a histórias literárias propriamente ditas; ensaios sobre obras específicas que, a partir de seus objetos particulares, projetam-se na questão geral da identidade literária do País; textos de autocrítica, cujos autores, tratando de suas próprias produções, as vinculam ao projeto geral de nacionalização da literatura -, tendo ainda caracterizado aqueles que considerei irredutíveis às categorias sugeridas; referi, finalmente, os desdobramentos da historiografia literária brasileira nos séculos XX e XXI, mencionando seu presente de descrédito e a incerteza de seu futuro.

Quanto a considerações sobre a versão efetivamente publicada, tenho notícia de duas resenhas, ambas deste ano de 2015. Uma delas, do professor Marcos Pasche, da Universidade Federal Rural do Rio de Janeiro, saiu na Revista da Academia Brasileira de Filologia (número XIV), e a outra, da professora Alva Martínez Teixeiro, da Universidade de Lisboa, na Colóquio Letras (número 189). Ambas as leituras, bastante analíticas, críticas e minuciosas, formulam juízos em geral favoráveis à obra: a primeira a considera "trabalho de grande extensão e de aguda 
relevância" (PASCHE, 2015, p. 186); a segunda, por sua vez, ponderando embora que, na apresentação, se encontrariam subvalorizadas as contribuições de Alfredo Bosi, José Guilherme Merquior, Massaud Moisés e José Aderaldo Castello, na comparação com o apreço manifestado relativamente às obras de Antonio Candido e Afrânio Coutinho, conclui que o trabalho "afigura-se essencial para um melhor conhecimento e valorização da atividade cultural, intelectual e historiográfica do Brasil oitocentista" (TEIXEIRO, 2015, p. 285).

Mas a História de Norberto é que suscitou mais comentários críticos.

O primeiro saiu no caderno "Ideias", do falecido Jornal do Brasil, no número de 27 de abril de 2002, em resenha de Isabel Lustosa. Matéria de página inteira, belamente ilustrada, continha, na medida das possibilidades do veículo, análise minuciosa da obra, tomando-a, sobretudo, como documento de interesse para a história social e cultural dos períodos do império e da colônia, sem qualquer observação, porém, sobre o trabalho da edição.

O segundo, assinado por Antônio Arnoni Prado, se publicou no "Mais!", da Folha de S. Paulo, do dia 28 de abril de 2002. Desenvolvia seus argumentos por um confronto entre duas histórias da literatura brasileira, por coincidência lançadas naquele ano, a de Joaquim Norberto e a de Nélson Werneck Sodré, a décima edição desta e a primeira em livro daquela. Conforme o resenhista, entre outras oposições cruciais a apartar uma obra da outra, a de Norberto se ressentiria de incompletude e caráter fragmentário, ao passo que a de Sodré pecaria por "excesso de sistematização e de simetrias", embora coincidissem num ponto: ambas ocupariam hoje um "lugar discreto ou meramente instrumental [...] no quadro histórico das nossas letras". Quanto ao trabalho de edição investido na História de Norberto - dizia a resenha -, teria um defeito capital: "tentar integrar, num conjunto fechado, as marcas intelectuais de um registro histórico que talvez ficassem melhor na indefinição circunstancial e episódica própria de intervenções pioneiras como as de Norberto [...]". Nas palavras do autor da resenha, assim, teria havido, por parte do organizador da edição, "excessivo desvelo", quando teria sido preferível deixar os textos do velho crítico e historiador fluminense na desordem de seus incipientes registros originários. De minha parte, como antes 
assinalei, creio que procede parcialmente o reparo, pois hoje me parecem artificiais os enxertos que providenciei na cabulosa História em questão; outras intervenções editoriais que fiz nos textos, contudo, me parecem não só legítimas, mas necessárias, pois talvez não seja exagero concluir que, levadas ao limite, as reservas do professor Prado implicam verdadeiro veto a reedições de obras como as de Norberto, pois qualquer tentativa de recuperá-las e recolocá-las em circulação desfiguraria "as marcas intelectuais de [seu] registro histórico", sendo, por conseguinte, recomendável que permaneçam sepultadas sob o peso de sua irremediável desimportância. Ora, não tenho dúvidas de que, até para se ajuizar da importância menor ou maior de um texto a condição mínima é o acesso material a ele, argumento que, a meu ver, justifica plenamente reedições - e reedições intervencionistas, desde que explicitem seus critérios -, reedições mesmo de materiais que, pelos nossos falíveis critérios de hoje, tendemos a considerar de duvidosa qualidade conceitual, como é o caso do texto de Norberto. Mas, se acho que a resenha tocou num ponto pertinente - esse da justificativa ou não da edição, e de seus critérios menos ou mais intervencionistas -, por outro lado me pareceu extravagante o motivo apontado para as intervenções promovidas pelo organizador: mais não teria sido do que uma "expansão de exageros" homóloga ao entusiasmo hiperbólico que dá o tom ao estilo de Norberto, com seus derramados e declamatórios elogios românticos à natureza e aos costumes brasileiros. Bem, salvo demonstração em contrário, temos aí um caso de superinterpretação, de resto nada incomum no campo das humanidades, e muito especialmente na área dos estudos literários.

Um pouco depois, no "Prosa e Verso" d'O Globo (número 8, de junho de 2002), a coluna fixa de Wilson Martins se ocuparia com a obra, assinalando que seu propósito seria apresentar "a primeira 'História' [...] da nossa literatura, [...] idealmente reconstruída". Entendo que a observação, muito sinteticamente, refere-se às minhas intervenções para a montagem da História norbertiana - objeto, como vimos, de crítica na matéria da Folha -, cujo resultado teria sido uma "reconstrução ideal" da obra, juízo que me parece neutro e descritivo, isto é, nem elogioso nem restritivo, embora, como disse antes, hoje eu mesmo faça restrições a certas liberdades que tomei no arranjo da edição. 
Seguiu-se, por fim, a análise crítica de Elias Thomé Saliba, publicada no "Caderno 2 / Cultura" d'O Estado de S. Paulo, na edição de 9 de junho de 2002. O autor, além de destacar o fato de a obra "torna[r] acessível aos leitores algumas das pioneiras reflexões que acompanharam a criação do País", no pressuposto de tratar-se de figura quase desconhecida, faz uma apresentação geral de Norberto, na moldura de sua época, comentando também detalhes de diversos textos incluídos no volume. Qualifica o volume como "preciosa coletânea", e assinala tratar-se de "criteriosa edição anotada".

Quanto ao Crítica reunida (1850-1892), volume em que, como já disse, José Américo Miranda, Maria Eunice e eu recolhemos a produção do mesmo Norberto no âmbito da crítica sensu stricto, foi objeto da coluna de Wilson Martins, já então transferida d'O Globo para o então agonizante Jornal do Brasil. Saiu no caderno "Ideias \& Livros", na edição de 14 de abril de 2007. No início do texto aparece, entre parênteses, a referência da obra, lançada dois anos antes. A partir daí, o autor parte para considerações sobre o processo de formação da história literária brasileira no século XIX, com certo destaque para o papel nele desempenhado por Norberto. No último parágrafo, citando Antonio Candido, consigna a Norberto o mérito de ter sido responsável pelas "edições mais completas e satisfatórias do [seu] tempo", e só então volta ao volume supostamente objeto da resenha, para fulminá-lo no seguinte veredicto: "A referida edição da Crítica reunida não corresponde a essas tradições; obra escolar de interesse apenas antológico". Bem, eu sou suspeito, mas discordo do juízo: a edição é cuidadosa e profusamente anotada, e conta com texto introdutório enxuto e correto, além de ter sido criativa e conceitualmente precisa na distribuição da matéria em partes homogêneas e coesas. "Escolar" só se no sentido de ter sido obra de scholars, e "antologia", absolutamente não é.

Podemos agora concluir, com uma notícia sumária do que está nos meus planos para este ano de 2015, a fim de encerrar esse ciclo de estudos que já se faz demasiadamente extenso.

Falei antes no ensaio de Álvares de Azevedo, intitulado "Literatura e civilização em Portugal", antes acolhido na ínte- 
gra no Historiografia da literatura brasileira: textos fundadores, e lá representado, na versão publicada, apenas por um pequeno trecho. Como acho que as edições desse texto até agora disponíveis são muito precárias, pretendo publicar, ainda este ano, a que tenho pronta, não sem antes, claro, submetê-la ao vernissage de rigor que precede às exposições. Tendo em vista 0 eruditismo juvenil que caracteriza o texto, além de um pequeno estudo introdutório, a edição será copiosamente anotada, e deve resultar num volumezinho de dimensões simpáticas.

Mas o empenho principal estará por conta de uma espécie de segunda edição da obra de Guilhermino César que, lá atrás, referi como um dos pontos de partida do trabalho que venho fazendo. É que, além de o livro encontrar-se há muito tempo fora de catálogo, meus estudos me conduziram a perceber certas lacunas no corpus reunido pelo professor Guilhermino, que à primeira vista me parecia exaustivo e definitivo. Assim, a edição que planejo, a fim de dar conta da contribuição estrangeira para a constituição da história literária do Brasil, não só seguirá critérios distintos dos aplicados por ele - pretendo adotar o mesmo modelo utilizado para a contribuição dos nacionais, observado nos dois volumes do Historiografia da literatura brasileira: textos fundadores -, como também contemplará alguns autores que lhe escaparam à malha fina. De saída, penso no francês Eugène de Monglave, cujo Cours de littérature portugaise et brésilienne parece ter-se perdido, mas do qual alguns trechos se podem recuperar, transcritos que são na História de Norberto. Penso também no espanhol Juan Valera - seu "De la poesia del Brasil" -, e no argentino Eduardo Perié - seu livro A literatura brasileira nos tempos coloniais do século XVI ao começo do XIX, publicado em português na cidade de Buenos Aires, no ano de 1885, além, a depender de confirmação pelas pesquisas, de alguns outros estrangeiros, como Richard Burton e José Mármol. Quanto aos portugueses, talvez haja acréscimos em relação aos arrolados por Guilhermino César - Herculano, Garrett e Gama e Castro -, de novo na dependência do desenvolvimento das pesquisas, sendo assim provável acrescentarem-se à coletânea contribuições de Freire de Carvalho, Lopes de Mendonça e Camilo Castelo Branco. Por outro lado, diferentemente do entendimento de Guilhermino César, acredito que será conceitualmente necessário, no arranjo do volume, conceder aos portugueses um tratamento especial, 
na suposição de que, pelo menos no século XIX (se não ainda hoje), não eram eles, do ponto de vista social e cultural, propriamente estrangeiros, por razões evidentes, embora o fossem pelo critério jurídico-político.

Sendo assim, acredito ter reconstituído com fidelidade a trajetória do longo ciclo de estudos em questão. Procurei recompor suas motivações iniciais, expor vacilações e dificuldades que o assinalaram, descrever seus principais resultados e, por fim, projetar os últimos produtos que dele ainda espero num futuro próximo. Fim de linha, portanto, e assim vou por aqui pingando o ponto final, na expectativa de que o relato de experiência que ora encerro possa de algum modo ser útil à formação dos estudantes que me distinguiram com sua atenção.

\section{REFERÊNCIAS}

AUERBACH, Erich. Introdução aos estudos literários. Tradução de José Paulo Paes. São Paulo: Cultrix, 1970.

CADERNOS do Centro de Pesquisas Literárias da PUCRS. Organização de Regina Zilberman e Maria Eunice Moreira. Porto Alegre: Pontifícia Universidade Católica do Rio Grande do Sul, Instituto de Letras e Artes, v. 1, n. 2, jun. de 1995.

CADERNOS do Centro de Pesquisas Literárias da PUCRS. Organização de Regina Zilberman e Maria Eunice Moreira. Porto Alegre: Pontifícia Universidade Católica do Rio Grande do Sul, Instituto de Letras e Artes, v. 5, n. 2, ago. de 1999.

CÉSAR, Guilhermino (Sel. e apres.). Historiadores e críticos do romantismo: 1 - a contribuição europeia: história e crítica literária. Rio de Janeiro: Livros Técnicos e Científicos; São Paulo: Edusp, 1978.

LUSTOSA, Isabel. Um intelectual na corte carioca. Jornal do Brasil, Rio de Janeiro, 27 abr. 2002. Caderno Ideias, p. 8.

MARTINS, Wilson. Histórias literárias. O Globo, Rio de Janeiro, 08 jun. 2002. Caderno Prosa \& Verso, p. 4.

. Rupturas e continuidades (4). Jornal do Brasil, Rio de Janeiro, 14 abr. 2007. Caderno Ideias \& Livros, p. 7. 
PARECER sobre a obra Uma literatura original nos trópicos: textos fundadores da historiografia literária brasileira, de Roberto Acízelo de Souza. São Paulo: Edusp, [2003].

PASCHE, Marcos; SOUZA, Roberto Acízelo de (Org.). Historiografia da literatura brasileira: textos fundadores (1825-1888). Rio de Janeiro: Caetés : FAPERJ, 2014. 2 v. Revista da Academia Brasileira de Filologia, Rio de Janeiro, n. XIV (nova fase), p. 185-188, primeiro semestre 2014.

PINHEIRO, Joaquim Caetano Fernandes. Historiografia da literatura brasileira: textos inaugurais. Organização de Roberto Acízelo de Souza. Rio de Janeiro: EdUERJ, 2007.

PRADO, Antônio Arnoni. Nostalgia incompleta e revolução discreta. Folha de S. Paulo, São Paulo, 28 abr. 2002. Caderno Mais, p. 3.

REIS, Francisco Sotero dos. Curso de literatura portuguesa e brasileira: fundamentos teóricos e autores brasileiros. Organização de Roberto Acízelo de Souza. Rio de Janeiro: Caetés : FAPERJ, 2014.

ROMERO, Sílvio. História da literatura brasileira, v. 2. 5. ed. Organizada e prefaciada por Nélson Romero. Rio de Janeiro: J. Olympio, 1953.

SALIBA, Elias Thomé. Um inventor da história literária brasileira. O Estado de S. Paulo, São Paulo, 09 jun. 2002. Caderno 2 / Cultura, p. 11.

SILVA, Joaquim Norberto de Sousa. Bosquejo da história da poesia brasileira. Edição, apresentação e notas de José Américo Miranda. Belo Horizonte: Ed. UFMG, 1997.

. Capítulos de história da literatura brasileira: e outros estudos. Edição e notas de José Américo Miranda e Maria Cecília Boechat. Belo Horizonte: Faculdade de Letras da UFMG, 2001.

. Crítica reunida: 1850-1892. Organização de José Américo Miranda, Maria Eunice Moreira e Roberto Acízelo de Souza. Porto Alegre: Nova Prova, 2005.

. História da literatura brasileira: e outros ensaios. Organização, apresentação e notas de Roberto Acízelo de Souza. Rio de Janeiro: Zé Mário Ed. : Fundação Biblioteca Nacional, 2002. 
SOUZA, Roberto Acízelo de (Org.). Historiografia da literatura brasileira: textos fundadores (1825-1888). Rio de Janeiro: Caetés : FAPERJ, 2014. $2 \mathrm{v}$.

. Introdução à historiografia da literatura brasileira. Rio de Janeiro: EdUERJ, 2007.

O império da eloquência: retórica e poética no Brasil oitocentista. Rio de Janeiro: EdUERJ; Niterói, RJ: EdUFF, 1999. Textos fundadores da historiografia literária brasileira: descrição da pesquisa e análise preliminar. Vínculo: revista de Letras da Unimontes, Montes Claros, MG, v. 3, n. 1, p. 21-43, dez. 2002.

TEIXEIRO, Alva Martínez. Historiografia da literatura brasileira: textos fundadores, de Roberto Acízelo de Souza. Colóquio Letras, Lisboa: Fundação Calouste Gulbenkian, v. 189, p. 283-285, maio 2015.

WELLEK, René. História da crítica moderna, v. 4. Tradução de Hildegard Feist. São Paulo: Herder : Edusp, 1972.

ZILBERMAN, Regina; MOREIRA, Maria Eunice (Org.). O berço do cânone: textos fundadores da história da literatura brasileira. Porto Alegre: Mercado Aberto, 1998.

\begin{abstract}
Nineteenth-century Brazilian literary historiography: a study cicle (1996-2015)

It is described a long cycle of a research on the founding works of the Brazilian literary history, from the initial idea to the publication of its results, while it is undertaken a reflection on the various aspects of the whole process.
\end{abstract}

Key-words: Brazilian literature; literary historiography; founding works. 